\title{
CEACAM7 Gene
}

National Cancer Institute

\section{Source}

National Cancer Institute. CEACAM7 Gene. NCI Thesaurus. Code C24293.

This gene is postulated to play a role in cell adhesion, however this role has not been substantiated. The gene is also a member of the immunoglobulin superfamily. 